\title{
Asymmetric Organocatalysts Supported on Vinyl Addition Polynorbornenes for Work in Aqueous Media
}

\author{
Irina K. Sagamanova, ${ }^{a}$ Sonia Sayalero, ${ }^{a}$ Sheila Martínez-Arranz, ${ }^{b}$ Ana C. Albéniz, ${ }^{* b}$ Miquel A. Pericàs ${ }^{* a, c}$
}

In an effort to identify novel polymer architectures suitable for the covalent supporting of catalysts, L-proline derivatives have been immobilized onto rationally designed vinyl addition polynorbornene (VA-PNB) resins through copper-catalyzed azide-alkyne cycloaddition (CuAAC) reactions. The fully saturated VA-PNB resins have been found to be optimal catalyst supports, the resulting proline-functionalized resins behaving as very active, easily recoverable and highly reusable organocatalysts for the asymmetric direct aldol reaction of benzaldehydes with ketones in aqueous media. The results show that the combination of modular, VA-PNB resins with proline derivatives and triazole linkers represents a promising strategy for the immobilization of organocatalytic species.

\section{Introduction}

As a result of increasing concerns on sustainable characteristics of chemical processes, the use of polymer-supported catalysts in synthetic chemistry has increased considerably in recent years. ${ }^{1}$ The covalent immobilization of catalytic species, offer important advantages. ${ }^{2}$ The catalytic activity of polymersupported species is importantly determined by the accessibility of the catalytic sites to the reactants, and is modulated by mass transfer limitations In this respect, different features of polymeric supports, such as solubility/swellability profile, degree of functionalization and the possible involvement of the polymer backbone in the catalytic reaction need all to be considered. $^{3}$ The choice of polymeric support is therefore an essential issue, since its structure and properties can importantly influence the course of chemical reactions mediated by catalysts immobilized on it. As a matter of fact, no single polymer structure would be optimal for every conceivable synthetic application. ${ }^{4}$ In spite of that, a vast majority of the applications reported so far rely on the use of polystyrenes as supports. ${ }^{1}$ Recently, we have developed a straightforward route to functionalized, vinyl addition (VA) polynorbornenes (PNB's). ${ }^{5}$ In this approach, haloalkyl substituted norbornenes, prepared by Diels-Alder reactions of cyclopentadiene and terminal 1-haloalkenes, are copolymerized with norbornene in the presence of $\left[\mathrm{Ni}\left(\mathrm{C}_{6} \mathrm{~F}_{5}\right)_{2}\left(\mathrm{SbPh}_{3}\right)_{2}\right]$, and the intermediate $\omega$-bromoalkyl substituted VA-PNB's are finally converted into the functional VA-PNB's by nucleophilic substitution (Scheme 1 ). ${ }^{5}$

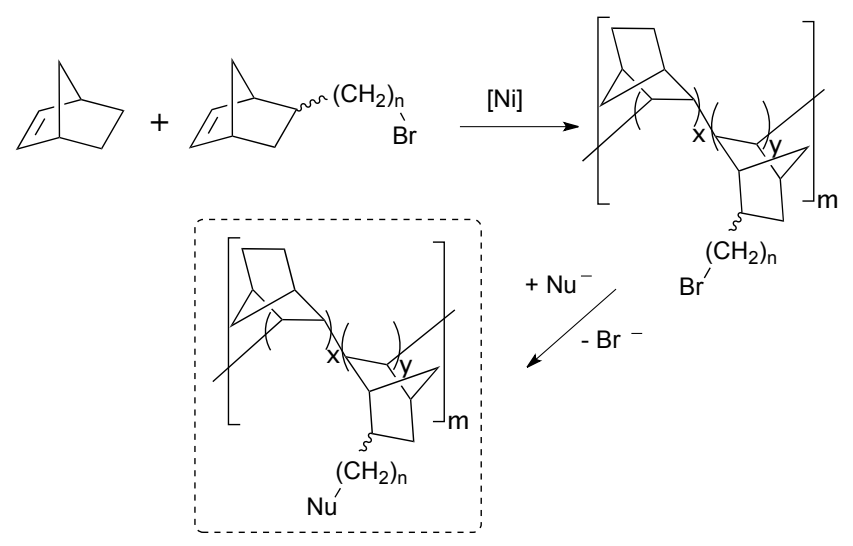

Scheme 1. Synthesis of functionalized VA-PNB polymers

In sharp contrast with polynorbornenes prepared by ringopening metathesis polymerization (ROMP), VA-PNB's do not contain in their skeletons carbon-carbon double bonds. For this reason, the possibility of uncontrolled side reactions triggered by these skeletal functional groups that could occur on ROMPPNB's is completely avoided in VA-PNB's (Figure 1).

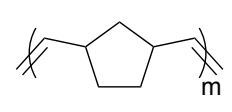

ROMP-PNB

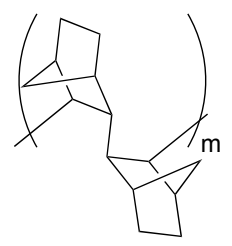

VA-PNB
Figure 1. General structures of ROMP-PNB and VA-PNB polymers. 
In spite of this potential limitation, ROMP-PNB's have been used as supports for the immobilization of reagents and catalysts. ${ }^{4}$ By the contrary, the chemically inert, fully saturated VA-PNB resins have not been evaluated so far for these applications. ${ }^{6}$ Our previous experience in the development of polymer-supported, easily recyclable organocatalysts for chemical processes with improved sustainability characteristics $^{7}$ led to the idea of anchoring suitably functionalized proline derivatives onto VA-PNB's with the double goal of assessing the suitability of these versatile polymers as inert supports for catalyst immobilization and of developing new robust, efficient and recyclable organocatalysts for asymmetric transformations. Herein we report the successful achievement of these goals through the application of the novel functional polymers 1-2 (Figure 2) as reusable catalysts for the highly stereoselective direct asymmetric aldol reaction in water. ${ }^{8}$ The reported strategy opens up new avenues for supporting multiple-function catalytic systems onto fully saturated VA-PNB supports.

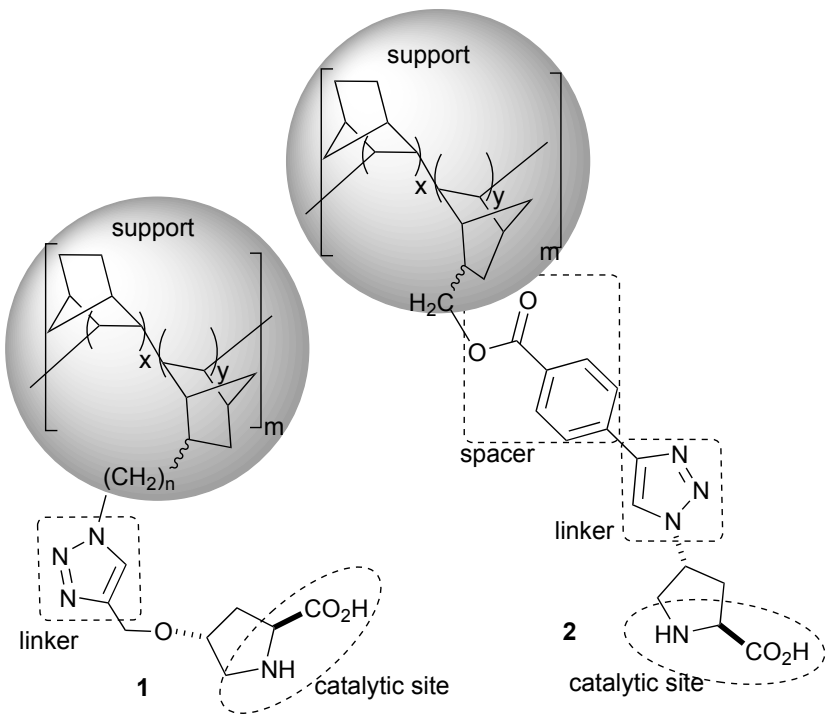

Figure 2. Schematic design of the polynorbornene-supported prolines developed in this work.

\section{Results and Discussion}

\section{Synthesis and characterization of the polynorbornene- supported catalysts}

Previous studies on the covalent immobilization of proline derivatives onto polystyrene (PS) resins through 1,2,3-triazole linkers have shown that the triazole units appear to play an active, synergistic role in catalytic processes mediated by these species in aqueous solvents. ${ }^{8 \mathrm{c}}$

For similar immobilization approaches to be used in the present instance, either alkyne- or azide-functionalized VA-PNB's should be first prepared. This has been done as illustrated in Scheme 2.

First, $\omega$-bromoalkyl functionalized VA-PNBs (3a-d) were prepared by $\mathrm{Ni}$-catayzed copolymerization of norbornene and $\omega$-bromoalkylnorbornenes according to our previously reported procedure. ${ }^{5}$ Two different lengths of the bromoalkyl chain $(\mathrm{n}=$ 1 and 4) were used to study the effect on catalytic behavior of increased separations between the functional units and the polymer chain. For each bromoalkyl chain length, two levels of functionalization were studied. Interestingly, the functionalization level can be adjusted by varying the relative amounts of norbornene and $\omega$-bromoalkylnorbornene used in the copolymerization. When the one-carbon spacer was used, the $\mathrm{x} / \mathrm{y}$ ratio varied between 1.1 and 1.6. This corresponds in both cases to rather heavily functionalized resins. With the long spacer, in turn, the $\mathrm{x} / \mathrm{y}$ composition ranged from 1.3 to 24.0 , thus covering a broad range in functionalization. The composition of the copolymers ( $\mathrm{x} / \mathrm{y}$ ratio) was determined in all cases by analysis of the bromine content in the polymer. From the stereochemical point of view, the different $\omega$ bromoalkylnorbornenes used for the preparation of the copolymers are mixtures of endo (major) and exo (minor) stereoisomers in a ratio close to endo: exo $=85: 15$.

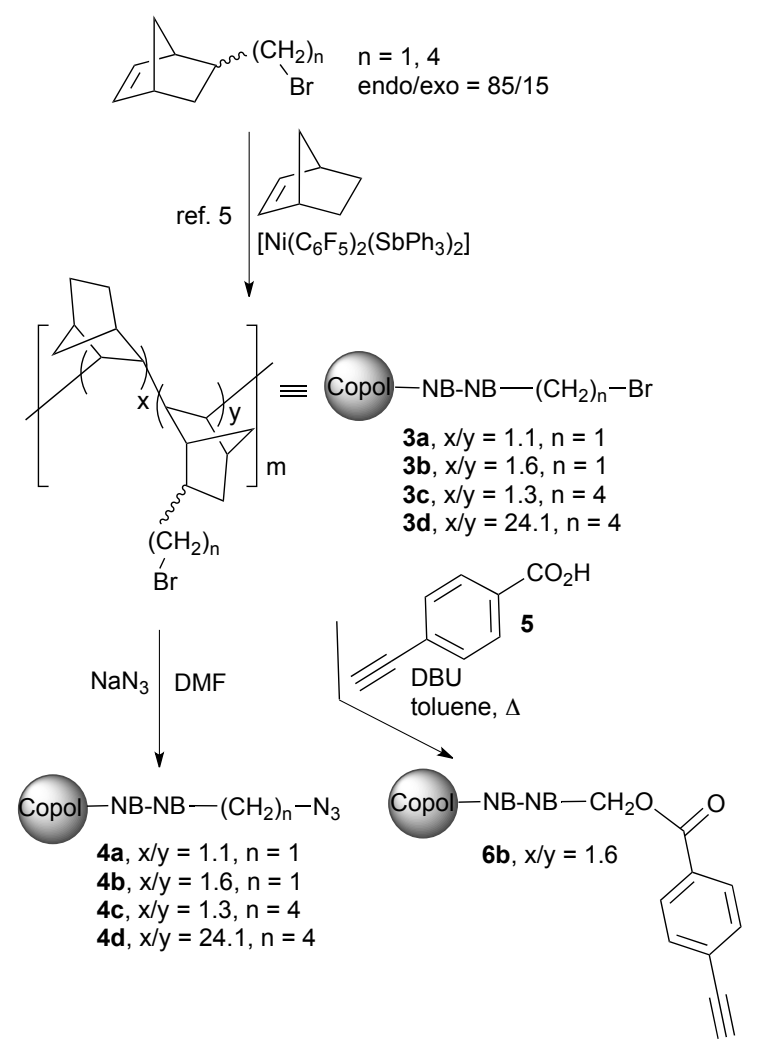

Scheme 2. Ready-to-click functional polymers employed in this study.

The azido function was introduced on these copolymers by nucleophilic substitution, by treatment with sodium azide in DMF. ${ }^{5}$ In this manner, $\omega$-azidoalkyl VA-PNB's 4a-d were readily prepared. On the other hand, the intermediate bromoalkyl VA-PNB's 3b $(\mathrm{x} / \mathrm{y}=1.6 ; \mathrm{n}=1)$ was treated with $p$ ethynylbenzoic acid (5) and DBU in toluene under reflux to 
afford the alkynyl-functionalized resin $\mathbf{6 b}$. While the substitution of bromide by azide was essentially complete in the preparation of $\mathbf{4 a - d}$, the corresponding substitution by $p$ ethynylbenzoate leading to $\mathbf{6 b}$ left unreacted some $31 \%$ of the bromomethyl groups present in $\mathbf{3 b}$. In any case, this was not problematic for the catalytic use of resins arising from $\mathbf{6 b}$, since these residual $\mathrm{CH}_{2} \mathrm{Br}$ groups turned out to be completely unreactive. The incorporation of the functional unit in polymer 6b was monitored spectroscopically. Thus, characteristic IR absorption bands for the ester and 4-ethynylphenyl groups gained intensity as the reaction proceeded, while the $\mathrm{C}-\mathrm{Br}$ absorption at $638 \mathrm{~cm}^{-1}$ was almost absent at the end of the process. Raman experiments also confirmed the presence of the alkyne $\left(2109 \mathrm{~cm}^{-1}\right)$ and remaining $\operatorname{Br}\left(638 \mathrm{~cm}^{-1}\right)$ in the polymer. In addition, the ${ }^{13} \mathrm{C}$ NMR spectrum of the polymer confirmed the presence of 4- ethynylphenyl group.

For the preparation of the catalytic resins 1a-d, diastereo- and enantiomerically pure $(2 S, 4 R)-N$-Boc-4-propargyloxyproline $7^{7 \mathrm{~b}}$ was used as the partner of resins 4a-d in copper-catalyzed alkyne-azide cycloaddition (CuAAC) reactions (Scheme 3, left). ${ }^{9} \quad$ After deprotection with trifluoroacetic acid in dichloromethane, the target prolines immobilized onto VAPNB supports 1a-d were obtained.

Catalyst 2, was readily prepared from copolymer $\mathbf{6 b}$ (Scheme 3, right). First, the alkynyl functionalized polymer was transformed into a fully protected form of the organocatalyst by a $\mathrm{CuAAC}$ reaction with the diastereo- and enantiomerically pure azido derivative $\mathbf{8}^{8 \mathrm{c}}$ Then, deprotection with trifluroacetic acid (TFA) in dichloromethane of $N$-Boc and $t$-butyl ester groups led to the ready-to-act catalytic resin 2.

It is interesting to note that whereas VA-PNB $\mathbf{6 b}$ is a white solid, soluble in common aprotic solvents of medium polarity, copolymer 2 generated in the click reaction is completely insoluble in the above mentioned media. This change of properties is of particular interest in connection with the recovery and reuse of the immobilized catalyst 2 . A similar behavior has already been noted in the preparation of $\boldsymbol{\omega}$ azidoalkyl VA-PNB's from the corresponding $\omega$-bromoalkyl precursors. ${ }^{5}$ Besides the structural changes introduced by the new substituent, a modification of the conformational behavior of the rigid bicyclic units in the polymer backbone during the cycloaddition plus deprotection process could also contribute to this change in the solubility behavior. ${ }^{10}$

The incorporation of the functional proline derivatives onto the copolymers via formation of a 1,2,3-triazole linker could be easily followed by IR spectroscopy. For catalysts 1a-d, characteristic IR absorption bands for the $N$-Boc and $t$-butyl ester groups (ca. 1737, 1699; ca. 1392, $1365 \mathrm{~cm}^{-1}$ ) were present after the click reaction, whereas the stretching band of the azido group (ca. $2091 \mathrm{~cm}^{-1}$ ) had completely disappeared. The presence of the free amino acid after the deprotection step was also confirmed spectroscopically $\left(1615-1631 \mathrm{~cm}^{-1}\right)$. In the case of catalyst 2, characteristic IR absorption bands for the $t$-butyl groups (ca. 1392, $1365 \mathrm{~cm}^{-1}$ ) and the ester group in the pethynylbenzoate fragment $\left(\mathrm{C}=\mathrm{O}, 1709 \mathrm{~cm}^{-1}\right)$ were present after the click reaction.

Table 1 summarizes the preparation of the copolymersupported organocatalysts 1a-d and 2: composition, functionalization $(f) .^{11,12 \mathrm{a}}$ yield ${ }^{12 \mathrm{~b}}$ and equilibrium swelling ratio (SR). ${ }^{13}$ As a general trend, the overall yield for the click and deprotection steps in the preparation of 1a-d was found to be in the $83-95 \%$ range. Somewhat surprisingly, the more intensely functionalized copolymers (1a and 1c) lead to the highest incorporation of catalytic unit (Yield column). On the other hand, the modification of the length in alkyl spacer connecting the polymer backbone with the functional units $(n=1$ or 4$)$ had little effect on the final functionalization yields (compare entries 1-2 and 3-4). In any case, and as we will see later, 1b presented optimal characteristics in catalysis.

The preparation of catalyst $\mathbf{2}$, where the complementary click approach is used (alkyne on resin plus soluble azide) reveals as slightly less efficient. As already discussed, the incorporation of the $p$-ethynylbenzoate fragment to the bromomethyl substituted VA-PNB 3b is not complete (ca. 69\%). In addition, the click reaction plus deprotection process required for the incorporation of the catalytic units also suffers from somewhat low efficiency, and the functionalization of the final resin indicates overall yields of $49 \%$ (from $3 \mathbf{b}$ ) or $75 \%$ (from $\mathbf{6 b}$ ). The occurrence of some solvolytic ester cleavage during the final deprotection step could explain the decreased yield from 6b. Solvent uptake data using different solvents (water, dimethyl sulfoxide and dichloromethane) indicate the swelling ability of the copolymers. The equilibrium swelling ratio (SR) measured for each solvent shows that copolymers $\mathbf{1}$ and $\mathbf{2}$ swelled better in dichloromethane than in water, while dimethyl sulfoxide afforded an intermediate result. These data correlate well with the experimental results in catalysis described in the following section. 


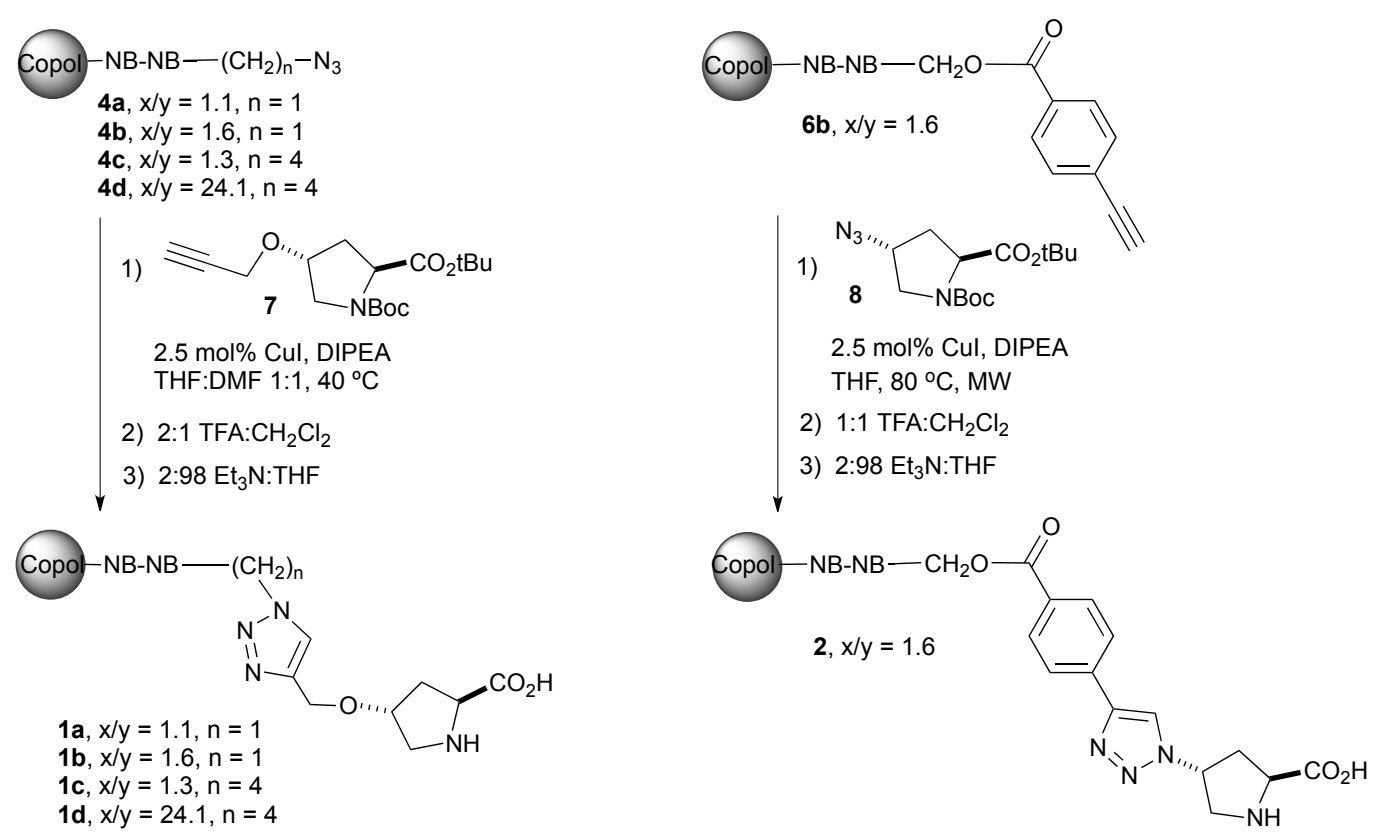

Scheme 3. Preparation of the VA-PNB immobilized catalysts 1a-d and 2.

Table 1. Characterization of polynorbornene-supported organocatalysts 1-2.

\begin{tabular}{|c|c|c|c|c|c|c|c|c|c|c|}
\hline Entry & Cat. & $\mathrm{x} / \mathrm{y}^{a}$ & $\mathrm{n}^{b}$ & $f_{0}\left(\mathrm{mmol} \mathrm{g}^{-1}\right)^{c, d}$ & $f_{\max }\left(\mathrm{mmol} \mathrm{g}^{-1}\right)^{e}$ & $f\left(\mathrm{mmol} \mathrm{g}^{-1}\right)^{d}$ & $\begin{array}{l}\text { Yield } \\
(\%)^{e}\end{array}$ & $\mathrm{H}_{2} \mathrm{O}$ & $\begin{array}{l}\text { SR }(\%)^{f} \\
\text { DMSO }\end{array}$ & $\mathrm{CH}_{2} \mathrm{Cl}_{2}$ \\
\hline 1 & 1a & 1.1 & 1 & 3.08 & 2.02 & 1.80 & 90 & 270 & 370 & 490 \\
\hline 2 & $1 \mathrm{~b}$ & 1.6 & 1 & 2.37 & 1.69 & 1.47 & 87 & 290 & 430 & 600 \\
\hline 3 & $1 \mathrm{c}$ & 1.3 & 4 & 2.96 & 1.97 & 1.88 & 95 & 360 & 440 & 590 \\
\hline 4 & 1d & 24.1 & 4 & 0.48 & 0.44 & 0.37 & 83 & 170 & 280 & 370 \\
\hline 5 & 2 & 1.6 & 1 & $2.98^{g}$ & 1.79 & 0.87 & 49 & 210 & 410 & 590 \\
\hline
\end{tabular}

${ }^{a} \mathrm{x} / \mathrm{y}=\mathrm{NB} / \mathrm{NB}\left(\mathrm{CH}_{2}\right)_{\mathrm{n}} \mathrm{X}$ ratio in the starting copolymer. ${ }^{\mathrm{b}}$ Chain length of the alkyl spacer in the functional norbornene monomer $\left(\mathrm{NB}\left(\mathrm{CH}_{2}\right)_{\mathrm{n}} \mathrm{X}\right) .{ }^{\circ}$ Functionalization of the starting copolymer (4a-d for $\mathbf{1 a}$-d, and $\mathbf{3 b}$ for $\mathbf{2}){ }^{\mathrm{d}}$ Calculated from the results of elemental analysis. See Ref. $11^{\mathrm{e}}$ Calculated with the formula given in Ref. 12. ${ }^{\mathrm{f}}$ Determined gravimetrically. See Ref. 13 and Supporting Information. ${ }^{\mathrm{g}}$ Determined by quantitative analysis of bromine in $\mathbf{3 b}$. See Ref. 11.

Taking into account the close relationship between physical surface properties of supported catalysts and its catalytic performance, the surface morphology of the new polymers was examined by SEM microscopy. Very interestingly, VAPNB supported catalysts 1a-c with high functionalization level $(\mathrm{x} / \mathrm{y}=1.1-1.6)$ show a more porous surface than catalyst $\mathbf{1 d}$ (Figure 3 ). Likewise, polymer 2 shows a porous surface comparable to that of $\mathbf{1 b}$ (Figure 4).

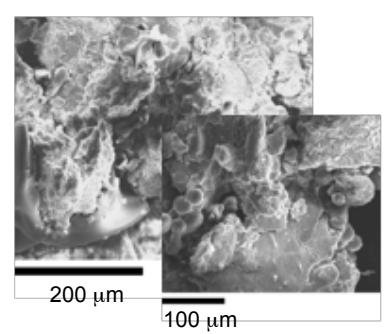

$1 \mathrm{a}$

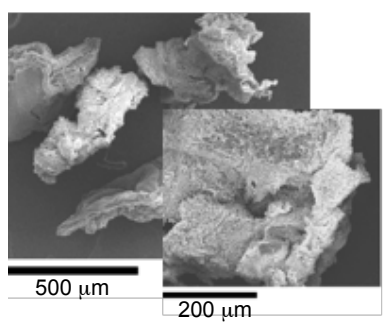

1c

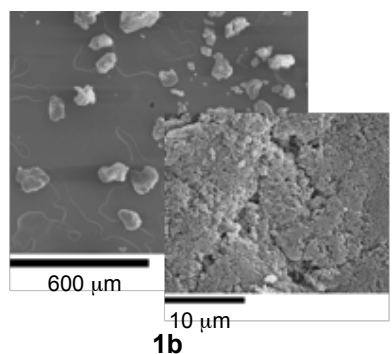

$1 \mathrm{~b}$

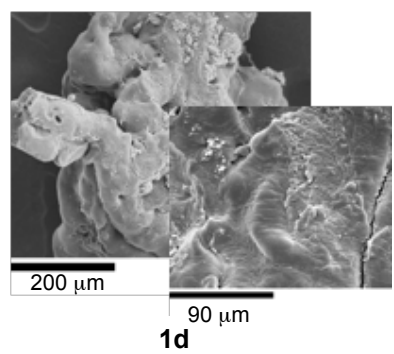

Figure 3. SEM images of VA-PNB supported organocatalysts 1a-d. 


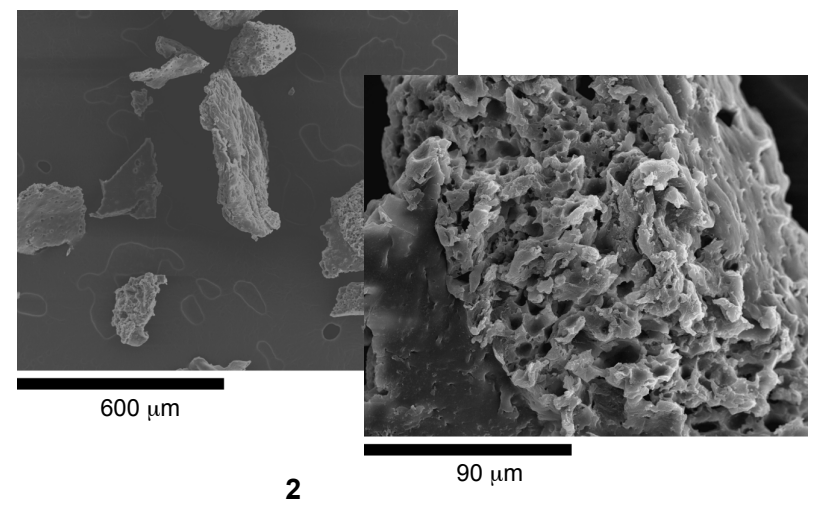

Figure 4. SEM images of VA-PNB supported organocatalyst 2.

Asymmetric aldol reaction mediated by catalysts 1a-d.

For the optimization of reaction conditions, we centered our attention on the use of benign reaction media (DMSO, water, and their binary mixtures) and on work under neat conditions with catalysts $\mathbf{1 a}$ and $\mathbf{1 b}$. The reactions were performed at room temperature with a $10 \mathrm{~mol} \%$ catalyst loading. The results of this study are summarized in Table 2 . A complete account of the performed solvent optimization studies can be found in the Supporting Information.

With both catalysts, optimal performance regarding yield (97-99\%) and stereoselectivity (89:11 to 91:9 anti:syn ratio, 90-91\% ee) was achieved in DMSO/water 83:17 mixtures (entries 4 and 9). Reactions in pure DMSO (entries 1 and 6) or in pure water (entries 2 and 7) led to decreased conversions and enantioselectivities, as the use of higher amounts of water also did (entries 3 and 8). This behavior parallels that of organocatalytic aldol reactions mediated by PS-proline immobilized through triazole linkers. ${ }^{8 b}$ Also in that case, the use binary mixtures of polar aprotic solvents and water had positive effects, ${ }^{14}$ importantly increasing both reaction rate and enantioselectivity. ${ }^{7 \mathrm{c}, 8}$

Likewise, the optimal solvent composition (DMSO/water 83:17) represents an optimal balance between ability for the establishing of a hydrogen bond network and VA-PNB swelling. ${ }^{8 \mathrm{c}}$ The combination of $\mathbf{1 b}$ and this solvent mixture (entry 9) exhibited a slightly better profile and, for this reason, its use in combination with acidic additives (entries 10 and 11) was also studied. The best result (96:4 anti:syn ratio, $96 \%$ ee, entry 11) was achieved with trifluoroacetic acid $(10 \mathrm{~mol} \%)$, and attempts to further accelerate the reaction at higher temperatures (see Supporting Information) did not lead to any practical improvement.

When the reaction was performed under solvent free conditions very low conversion and moderate stereoselectivity were observed (entries 5 and 12). However, performing the reaction in a ball-mill, ${ }^{15}$ with the use of $p$ nitrobenzaldehyde and cyclohexanone in essentially stoichiometric amounts, resulted in significantly better conversión after a notably short reaction time, although the recorded stereoselectivity continued to be only moderate (entry13).

Table 2. Solvent effect on the aldol reaction of cyclohexanone with $p$-nitrobenzaldehyde catalyzed by polymers $\mathbf{1} \mathbf{a}-\mathbf{b} .^{a}$

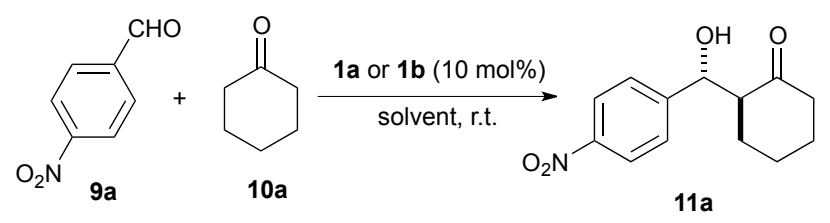

\begin{tabular}{|c|c|c|c|c|c|c|}
\hline Entry & Cat. & Solvent & $\begin{array}{l}\text { Time } \\
\text { (h) }\end{array}$ & Conv. ${ }^{b, c}$ & $\begin{array}{l}\text { anti: } \\
\text { syn }^{b}\end{array}$ & $\begin{array}{l}\text { ee } \\
\text { anti }^{d} \\
(\%)\end{array}$ \\
\hline 1 & $1 \mathrm{a}$ & DMSO & 21 & 61 & $74: 26$ & 91 \\
\hline 2 & $1 \mathrm{a}$ & $\mathrm{H}_{2} \mathrm{O}$ & 21 & 74 & $71: 29$ & 73 \\
\hline 3 & $1 \mathrm{a}$ & $\begin{array}{c}\mathrm{DMSO} / \\
\mathrm{H}_{2} \mathrm{O} \\
(50 / 50)\end{array}$ & 21 & 94 & $81: 19$ & 85 \\
\hline 4 & $1 \mathrm{a}$ & $\begin{array}{c}\text { DMSO/ } \\
\mathrm{H}_{2} \mathrm{O} \\
(83 / 17)\end{array}$ & 16 & $100(97)$ & $89: 11$ & 90 \\
\hline 5 & $1 \mathrm{a}$ & neat & 21 & 10 & $77: 23$ & 76 \\
\hline 6 & $1 b$ & DMSO & 21 & 82 & $76: 24$ & 92 \\
\hline 7 & $1 b$ & $\mathrm{H}_{2} \mathrm{O}$ & 21 & 81 & $79: 21$ & 78 \\
\hline 8 & $1 b$ & $\begin{array}{c}\mathrm{DMSO} / \\
\mathrm{H}_{2} \mathrm{O} \\
(50 / 50)\end{array}$ & 21 & 96 & $86: 14$ & 93 \\
\hline 9 & $1 b$ & $\begin{array}{c}\mathrm{DMSO} / \\
\mathrm{H}_{2} \mathrm{O} \\
(83 / 17)\end{array}$ & 19 & $100(98)$ & $91: 9$ & 91 \\
\hline 10 & $1 b$ & $\begin{array}{c}\mathrm{DMSO} / \\
\mathrm{H}_{2} \mathrm{O} \\
(83 / 17)^{e}\end{array}$ & 21 & $100(97)$ & $92: 8$ & 93 \\
\hline 11 & $1 b$ & $\begin{array}{c}\mathrm{DMSO} / \\
\mathrm{H}_{2} \mathrm{O} \\
(83 / 17)^{f}\end{array}$ & 21 & $99(90)$ & $96: 4$ & 96 \\
\hline 12 & $1 b$ & neat & 21 & 17 & $77: 23$ & 75 \\
\hline 13 & $1 b$ & neat $^{g}$ & 6.5 & 94 & $78: 22$ & 76 \\
\hline
\end{tabular}

a Reactions were performed with $\mathbf{1 a}$ or $\mathbf{1 b}(0.015 \mathrm{mmol}), p$ nitrobenzaldehyde (9a, $0.15 \mathrm{mmol})$ and cyclohexanone (10a, $0.75 \mathrm{mmol})$ in the indicated solvents $(54 \mu \mathrm{L}) .{ }^{b}$ By ${ }^{1} \mathrm{H}$ NMR on the reaction crude. ${ }^{c}$ The combined yield of isolated diastereomers is given in parentheses. ${ }^{d}$ By chiral HPLC. ${ }^{e} p$-Nitrobenzoic acid $(0.022 \mathrm{mmol})$ was used as an additive. ${ }^{f}$ Trifluoroacetic acid $(0.015 \mathrm{mmol}){ }^{g}$ Reaction performed in a ball-mill: 9a (89 mg, $0.59 \mathrm{mmol}), \mathbf{1 0 a}(67 \mu \mathrm{L}, 0.65 \mathrm{mmol}), 1 \mathbf{b}(40 \mathrm{mg}$, $0.059 \mathrm{mmol}$ ) and 60 zirconium oxide balls, rotation speed of 250-400 rpm..

It became apparent from these optimization studies that the best reaction conditions consisted in using $10 \mathrm{~mol} \%$ of catalyst in combination of $10 \mathrm{~mol} \%$ of TFA as an additive, a 
mixture DMSO: $\mathrm{H}_{2} \mathrm{O}(87: 13)$ as solvent and performing the reactions at room temperature. The transferability of these conditions was next checked by performing the reaction of 9a with 10a under catalysis by 1a-d (Table 3). Catalysts 1a, 1b and 1c showed similar behavior in terms of conversion, diastereo- and enantioselectivity (entries 1-3). Copolymer 1d, in turn, led to much lower conversion and decreased stereoselectivity (entry 4). This provides clear indication that the functionalization level of the catalytic polymers (1d is much less functionalized than 1a-c) has a significant influence on their performance. An examination of the effect of the amount of catalyst $\mathbf{1 b}$ (entries 5-6) showed that catalyst loading could be reduced to $5 \mathrm{~mol} \%$, but at the expense of increased reaction times. Thus, after $42 \mathrm{~h}$ conversion was only $73 \%$, while diastereoselectivity and enantioselectivity kept at the same level (entry 5). Conversely, when $20 \mathrm{~mol} \%$ of catalyst was used (entry 6), a noticeable increase in reaction rate was observed, the process being essentially complete in only $13 \mathrm{~h}$.

Table 3. Benchmarking of VA-PNB supported catalysts 1a-d in the aldol reaction of cyclohexanone with $p$-nitrobenzaldehyde. ${ }^{a}$

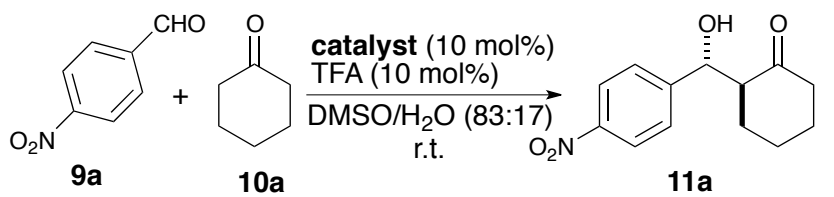

\begin{tabular}{ccccccc}
\hline Entry & Cat. & $\begin{array}{c}\text { Time } \\
(\mathrm{h})\end{array}$ & $\begin{array}{c}\text { Conv. } \\
(\%)^{b}\end{array}$ & $\begin{array}{c}\text { Yield } \\
(\%)^{c}\end{array}$ & $\begin{array}{c}a^{2} t i: \\
\text { syn }^{b}\end{array}$ & $\begin{array}{c}\text { ee anti } \\
(\%)^{d}\end{array}$ \\
\hline 1 & $\mathbf{1 a}$ & 23 & 95 & 88 & $96: 4$ & 96 \\
2 & $\mathbf{1 b}$ & 23 & 96 & 90 & $96: 4$ & 96 \\
3 & $\mathbf{1 c}$ & 23 & 93 & 80 & $96: 4$ & 96 \\
4 & $\mathbf{1 d}$ & 23 & 43 & 38 & $89: 11$ & 85 \\
5 & $\mathbf{1 b}^{e}$ & 42 & 73 & 64 & $96: 4$ & 96 \\
6 & $\mathbf{1 b}^{f}$ & 13 & 95 & 91 & $96: 4$ & 96
\end{tabular}

${ }^{a}$ Reactions were performed with resin $1(0.015 \mathrm{mmol}), 9 a(0.15 \mathrm{mmol})$, 10a $(0.75 \mathrm{mmol})$ in DMSO/water $(83: 17,54 \mu \mathrm{L}) .{ }^{b}$ By ${ }^{1} \mathrm{H}$ NMR on the reaction crude. ${ }^{c}$ Combined yield of isolated anti:syn diastereomers. ${ }^{d}$ By chiral HPLC. ${ }^{e} 5 \mathrm{~mol} \%$ catalyst used. ${ }^{f} 20 \mathrm{~mol} \%$ catalyst used.
We then set out to explore the applicability of $\mathbf{1 b}$ with respect to the aldehyde reaction partners. As it can be seen in Scheme 4, a wide range of aromatic aldehydes can effectively participate in this reaction affording the anti aldol products in very high yields and with both, high diastereoand enantioselectivity. As a general trend, reactions performed in the absence of TFA additive required slightly longer reaction times. Although higher yields were normally achieved in the absence of TFA, stereoselectivity slightly eroded in these experiments (11a,f-g,i-j), so that the convenience or not of using this additive has to be evaluated in each particular case.

These results show that VA-PNB supported proline 1b works in close parallelism to other amphiphilic polymeric proline derivatives that have proven to be efficient catalysts for the asymmetric aldol reactions of ketones and benzaldehydes in aqueous reaction conditions, ${ }^{7 \mathrm{c}, 8 \mathrm{~b}-\mathrm{c}, 17}$ and even outperforms the first reported monomeric proline derivative exhibiting aldolase-like behavior. ${ }^{18}$ 


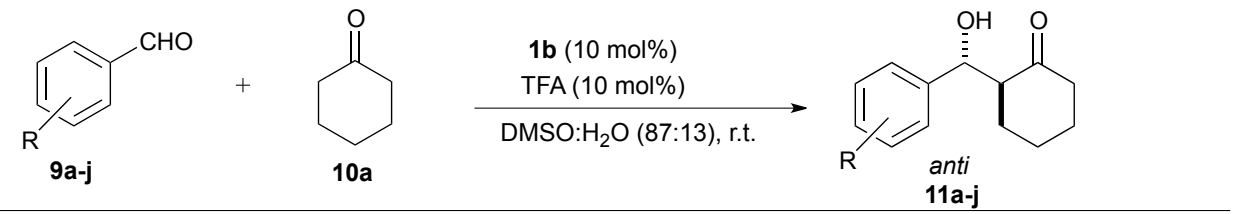<smiles>O=C1CCCCC1[C@H](O)c1ccc([N+](=O)[O-])cc1</smiles>

11a, $23 \mathrm{~h}, 90 \%$ yield $^{b}$ 96:4 anti:syn ${ }^{c}, 96 \%$ ee ${ }^{d}$

11a, $21 \mathrm{~h}^{f}, 98 \%$ yield $^{b}$ 91:1 anti:syn ${ }^{c}, 91 \%$ ee ${ }^{d}$<smiles>O=C1CCCCC1[C@H](O)c1ccc(C(F)(F)F)cc1</smiles>

11 e, $93 \mathrm{~h}, 87 \%$ yield $^{b}$ 96:4 anti:syn ${ }^{c}, 97 \%$ ee<smiles>O=C1CCCC[C@H]1[C@H](O)c1ccc2ccccc2c1</smiles>

$11 \mathrm{i}, 88 \mathrm{~h}, 63 \%$ yield $^{e}$ 96:4 anti:syn ${ }^{c}, 91 \%$ ee ${ }^{d}$

11i, $96 \mathrm{~h}^{f}, 75 \%$ yield $^{b}$ 90:10 anti:syn ${ }^{c}, 90 \%$ ee<smiles>O=C1CCCC[C@H]1[C@H](O)c1ccccc1[N+](=O)[O-]</smiles>

11b, 47 h, 94\% yield 96:4 anti:syn ${ }^{c}, 96 \%$ ee<smiles>O=C1CCCC[C@H]1[C@H](O)c1ccccc1C(F)(F)F</smiles>

11f, 110 h, $65 \%$ yield $^{b}$ 98:2 anti:syn ${ }^{c}, 96 \%$ ee ${ }^{d}$ $11 f, 110 \mathrm{~h}^{f}, 98 \%$ yield ${ }^{b}$ 97:3 anti:syn ${ }^{c}, 91 \%$ ee<smiles>O=C1CCCC[C@H]1[C@H](O)c1ccc(Br)cc1</smiles>

11j, 47 h, 79\% yield ${ }^{b}$ 96:4 anti:syn ${ }^{c}, 96 \%$ ee ${ }^{d}$

$11 \mathrm{j}, 65 \mathrm{~h}^{f}, 98 \%$ yield 93:7 anti:syn ${ }^{c}, 93 \%$ ee ${ }^{d}$<smiles>O=C1CCCC[C@H]1[C@H](O)c1cccc([N+](=O)[O-])c1</smiles>

11c, 47 h, $93 \%$ yield $^{b}$ 95:5 anti:syn ${ }^{c}, 97 \%$ ee ${ }^{d}$ 97:3 anti:syn ${ }^{c}, 96 \%$ ee 11d, 43 h, $88 \%$ yield $^{b}$<smiles>N#Cc1ccc([C@@H](O)[C@H]2CCCCC2=O)cc1</smiles><smiles>CC(=O)c1ccc([C@@H](O)[C@H]2CCCCC2=O)cc1</smiles>

11g, 93 h, 74\% yield $b$ 95:5 anti:syn ${ }^{c}, 95 \%$ ee ${ }^{d}$

11h, 46 h, 81\% yield $b$ 97:3 anti:syn ${ }^{c}, 96 \%$ ee ${ }^{d}$

11g, $96 \mathrm{~h}^{f}, 95 \%$ yield $^{b}$

90:10 anti:syn ${ }^{c}, 91 \%$ ee

\begin{abstract}
${ }^{a}$ Reaction conditions: aldehyde $(0.15 \mathrm{mmol}), \mathbf{1 0 a}(0.75 \mathrm{mmol}), \mathbf{1 b}(10.2 \mathrm{mg}, 0.015 \mathrm{mmol})$, TFA (0.015 mmol) in DMSO:H2O (83:17, $\left.54 \mu \mathrm{L}\right)$ at room temperature. ${ }^{b}$ Combined yield of the isolated diastereomers. ${ }^{c}$ By ${ }^{1} \mathrm{H}$ NMR on the reaction crude. ${ }^{d}$ By chiral HPLC of $11 .{ }^{e}$ Isolated yield of anti isomer. ${ }^{f}$ Without TFA additive.
\end{abstract}

Scheme 4. Substrate scope of the aldol reaction catalyzed by $\mathbf{1 b}{ }^{a}$

\section{Asymmetric aldol reaction mediated by catalyst 2.}

Catalyst 2 was designed with the goal of increasing the catalytic activity and stereoselectivity depicted by $\mathbf{1 a - c}$. We anticipated that the structural changes introduced in $\mathbf{2}$ would modify the hydrophobic/hydrophilic balance in the amphiphilic catalyst, leading to higher catalytic activity in water and to higher levels of stereocontrol in this reaction media. ${ }^{8,17}$

As a common characteristic, proline and pyrrolidine derivatives able to catalyze aldol reactions in aqueous media display well differentiated molecular regions with hydrophobic and hydrophilic characters, as it is known for type-I aldolases. In polymer-supported prolines, the extended polymer backbone efficiently mimics the hydrophobic pocket of the natural enzymes, while the functional units need to provide the hydrophilic environment where the reaction takes place. The same behavior could be expected in case of copolymer $\mathbf{2}$ where, according to precedents, ${ }^{8 \mathrm{c}}$ the triazole unit could play the double role of grafting the proline unit onto the polymer and allowing the formation of a hydrogen bond network connecting the linker with the amino and carboxy groups in the catalytic unit. In addition, the $p$-phenylene spacer present in $\mathbf{2}$ could also improve the catalyst activity and stereoselectivity because of the increased separation between the hydrophilic, catalytically active moiety and the hydrophobic polymer backbone, as previously noted with polystyrene-supported prolines. $^{7 \mathrm{c}}$ The study on the catalytic behavior of 2 in water was initiated by using $p$-nitrobenzaldehyde (9a) and cyclohexanone (10a) as model substrates in the aldol addition (see Supporting Information for details). Pleasingly, the reaction proceeded nicely in water, affording aldol 11a in $22 \mathrm{~h}$ with excellent yield (90\%) and stereoselectivity (95:5 anti:syn ratio, 96\% ee). Identical stereoselectivity was 
recorded when the reaction was conducted in DMSO: $\mathrm{H}_{2} \mathrm{O}$ (50:50) or DMF: $\mathrm{H}_{2} \mathrm{O}$ (50:50) mixtures. In these solvent mixtures, a slightly improved yield $(95 \%)$ was also recorded. In practice, a (50:50) mixture of DMF and water was the solvent of choice for these reactions. In this media, the reactions catalyzed by $\mathbf{2}$ provided the aldol adducts 11a-l with excellent yield and stereoselectivity, in shorter reaction times than with catalyst $\mathbf{1 b}$ and without the need of added acid (Scheme 5). It thus appears that the combination of the polynorbornene skeleton, the $p$-phenylenecarboxylate spacer and the triazole linker leads to a significant improvement of the catalytic activity of the proline unit in aqueous media. Reactions involving cyclopentanone (10b) and 4-pyranone (10c) as pronucleophiles were remarkably fast, providing the corresponding anti-aldol products $11 \mathrm{k}-\mathbf{l}$ in very high yield and good stereoselectivity. ${ }^{15 b, 17 d, 20}$ In general, products $\mathbf{1 1}$ were obtained in high purity after a simple filtration (to recover 2), extraction with dichloromethane and evaporation, no further purification being required. On the negative side, when the use of $\mathbf{2}$ was attempted in the aldol reactions of p-nitrobenzaldehyde (9a) with acyclic ketones such as acetone and hydroxyacetone under the optimized conditions in Scheme 5, very low conversions $(<5 \%)$ were recorded after $48 \mathrm{~h}$.<smiles>[R]c1ccc(C=O)cc1</smiles>

$9 a-j$<smiles>[X]C1CCC(=O)C1</smiles>

10a-c

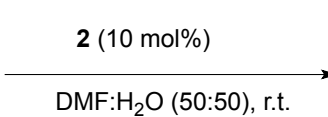

DMF: $\mathrm{H}_{2} \mathrm{O}(50: 50)$, r.t.

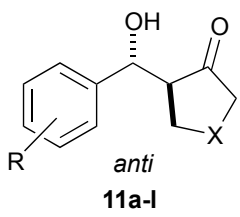

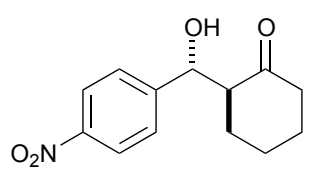

11a, 22 h, 97\% yield ${ }^{b}$ 96:4 anti:syn ${ }^{c}, 97 \%$ ee ${ }^{d}$ $\mathrm{X}=-\mathrm{CH}_{2} \mathrm{CH}_{2^{-}},-\mathrm{CH}_{2^{-}},-\mathrm{OCH}_{2^{-}}$

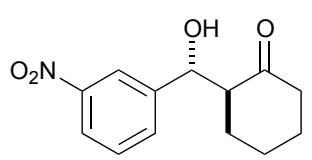

11c, $26 \mathrm{~h}, 86 \%$ yield $^{b}$ 97:3 anti:syn ${ }^{c}, 97 \%$ ee ${ }^{d}$ $97: 3$ anti:syn ${ }^{c},>99 \%$ ee ${ }^{d}$

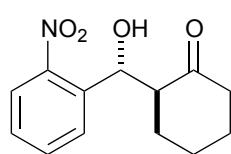

11b, 35 h, 69\% yield<smiles>O=C1CCCC[C@H]1[C@H](O)c1ccccc1C(F)(F)F</smiles>

11f, $110 \mathrm{~h}, 55 \%$ yield $^{b}$ 98:2 anti:syn ${ }^{c}, 94 \%$ ee<smiles>O=C1CCCCC1[C@H](O)c1ccccc1</smiles>

11g, 82 h, $80 \%$ yield $^{b}$ 93:7 anti:syn ${ }^{c}, 95 \%$ ee ${ }^{d}$<smiles>N#Cc1ccc([C@@H](O)[C@H]2CCCCC2=O)cc1</smiles>

11d, $23 \mathrm{~h}, 97 \%$ yield $^{b}$ 96:4 anti:syn ${ }^{c}, 97 \%$ ee ${ }^{d}$<smiles>O=C1CCCC[C@H]1[C@H](O)c1ccc(C(F)(F)F)cc1</smiles>

11e, $26 \mathrm{~h}, 93 \%$ yield $^{b}$ 95:5 anti:syn ${ }^{c}, 96 \%$ ee $^{d}$<smiles>O=C1CCCC[C@H]1[C@H](O)c1ccc2ccccc2c1</smiles>

$11 i, 82 \mathrm{~h}, 76 \%$ yielde $^{e}$ 95:5 anti:syn ${ }^{c}, 95 \%$ ee ${ }^{d}$

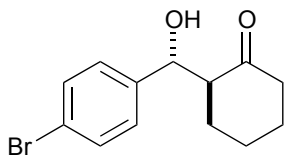

11j, 44 h, 99\% yield ${ }^{b}$ 95:5 anti:syn ${ }^{c}, 97 \%$ ee<smiles>O=C1CCCC1C(O)c1ccc([N+](=O)[O-])cc1</smiles>

$11 \mathbf{k}, 4 \mathrm{~h}, 93 \%$ yield $^{b}$ 76:24 anti:syn ${ }^{c}, 90 \%$ ee<smiles>COC(=O)c1ccc([C@@H](O)[C@H]2CCCCC2=O)cc1</smiles>

11h, 46 h, 95\% yield ${ }^{b}$ 96:4 anti:syn ${ }^{c}, 96 \%$ ee

\footnotetext{
${ }^{a}$ Reaction conditions: 9a-j $(0.15 \mathrm{mmol}), \mathbf{1 0 a}-\mathbf{c}(0.75 \mathrm{mmol})$, and $2(17 \mathrm{mg}, 0.015 \mathrm{mmol})$ in DMF: $\mathrm{H}_{2} \mathrm{O}(50: 50,54 \mu \mathrm{L})$ at room temperature. ${ }^{b}$ Combined yield of the isolated diastereomers after flash chromatography. ${ }^{c} \mathrm{By}{ }^{1} \mathrm{H}$ NMR on the reaction crude. ${ }^{d}$ By chiral HPLC of $11 .{ }^{e}$ Isolated yield of anti isomer.
}

Scheme 5. Substrate scope of the aldol reaction catalyzed by $2{ }^{a}$

\section{Catalysts recycling and reuse.}

To show the recyclability of polymers $\mathbf{1 b}$ and $\mathbf{2}$, two series of experiments were planned where single samples of these catalytic copolymers were repeatedly used at constant reaction time to mediate the aldol addition of cyclohexanone (10a) to $p$-nitrobenzaldehyde (9a) leading to 11a. The results of these studies have been summarized in Figure 5. The insoluble nature of the polymer allows for catalyst recovery by performing a simple filtration. Thus, after each run, the catalyst was readily recovered from the reaction mixture, washed and reused in the next reaction cycle (see Supporting Information).

Copolymer 1b was recycled seven times affording the aldol product with constant stereoselectivity and with only marginal decrease of catalytic activity in every cycle. IR analysis of the catalyst after recycling did not show any difference with the initial polymer. In an attempt to understand the origin of the observed decrease in catalytic activity, SEM studies were performed to monitor the change of the catalyst surface morphology. Compared with fresh catalyst $\mathbf{1 b}$, a very similar surface morphology was observed after the seventh run. This observation indicates that $\mathbf{1 b}$ does 
not experience structural collapse with repeated use. On the other hand, it was found that the $\% \mathrm{~N}$ determined by elemental analysis decreased after recycling, which was indicative that leaching of catalytic proline units from the copolymer backbone takes place to some extent. Catalyst $\mathbf{2}$, on the contrary, could be recycled and reused for at least seven runs without any appreciable loss in yield or in stereoselectivity. The polymer presented similar IR spectra and the same surface morphology before and after recycling. Furthermore, it was found that the $\% \mathrm{~N}$ determined by elemental analysis remained unchanged after recycling (see Supporting Information). It is thus clear that the presence of the $p$-phenylenecarboxylate spacer has a notable and very positive effect on the chemical stability of the polynorbornene-supported organocatalyst.
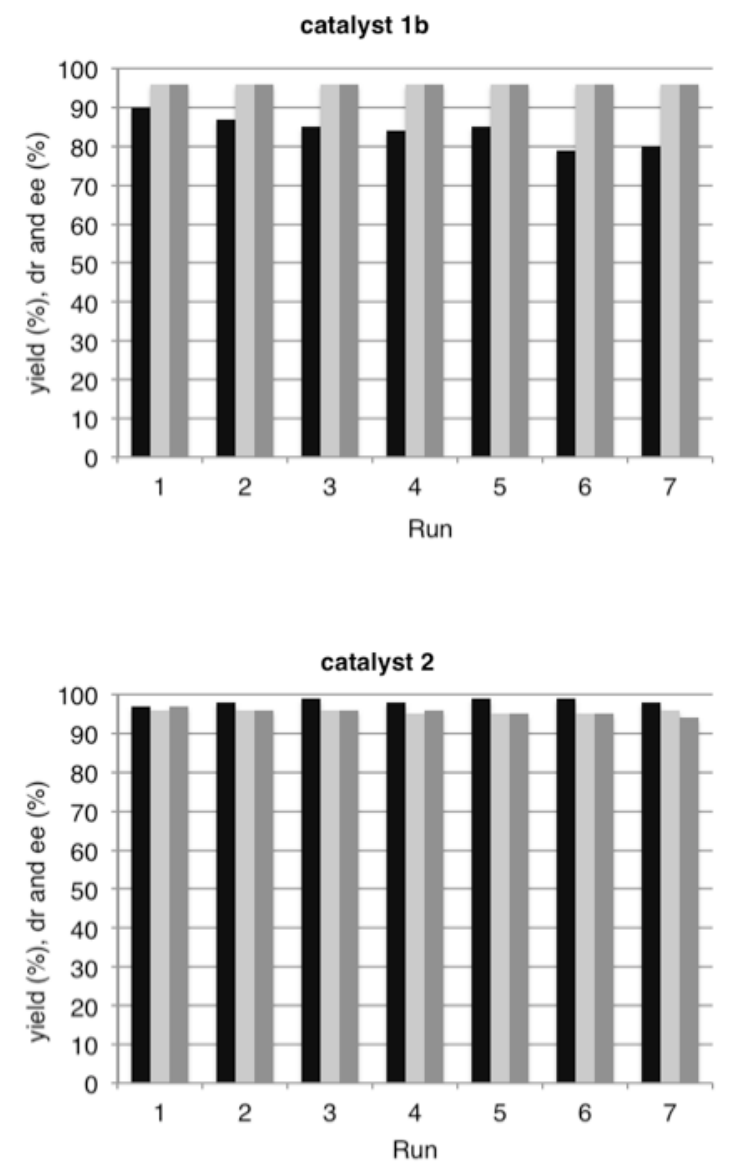

Figure 5. Catalyst recycling experiments in the aldol addition of cyclohexanone (10a) to $p$-nitrobenzaldehyde (9a) leading to $\mathbf{1 1 a}$ under optimized conditions with catalysts $\mathbf{1 b}$ and 2. Black bars: yield (\%); pale gray bars: $d r$; gray bars: ee $(\%)$.

\section{Conclusions}

In summary, we have successfully developed a family of modified prolines anchored onto VA-PNB's through two complementary alkyne-azide click reactions. The versatility of these species as organocatalysts has been also illustrated by their application in asymmetric aldol additions of ketone pronucleophiles to aromatic aldehydes in a variety of reaction conditions. Polynorbornene-supported proline has shown excellent performance in this particular aldol transformation in an aqueous environment, and the robustness of the new polymeric catalysts has been demonstrated by the possibility of extending its use for up to seven cycles in the aldol reaction of cyclohexanone and $p$ nitrobenzaldehyde. These results show that VA-PNB's can be considered as viable alternatives to well-established polystyrene resins as supports for the immobilization of catalysts. In addition, the absence of unsaturations in the polymer backbone of VA-PNB's should make these polymers transparent to UV light and therefore, could greatly facilitate the use of catalysts supported on these resins in photocatalytic processes. Further applications of VA-PNB's as catalysts supports, dictated by the structural characteristics of these copolymers, are now in progress in our laboratories.

\section{Experimental Section}

\section{Synthesis of catalysts 1a-d.}

1a: $t$-Butyl $(2 S, 4 R)-N$-Boc-4-propargyloxyprolinate 7 (600 $\mathrm{mg}, 1.84 \mathrm{mmol}), N, N$-diisopropylethylamine $(2.5 \mathrm{~mL}, 14.20$ mmol) and copper(I) iodide $(6.7 \mathrm{mg}, 0.035 \mathrm{mmol})$ were added to a suspension of copolymer 4a (Copol-NB$\left.\mathrm{NBCH}_{2} \mathrm{~N}_{3} \mathrm{x} / \mathrm{y}=1.1: 1, \mathrm{n}=1 ; 460 \mathrm{mg}, f=3.084 \mathrm{mmol} \mathrm{g}^{-1}\right)$ in a DMF:THF 1:1 mixture $(9 \mathrm{~mL})$ placed in a flask under $\mathrm{N}_{2}$. The reaction mixture was shaken at $40{ }^{\circ} \mathrm{C}$ for $24 \mathrm{~h}$, the reaction progress being monitored by FTIR. When the IR band of the azido group had completely disappeared, the polymer was collected by filtration, sequentially washed with $\mathrm{H}_{2} \mathrm{O}(40 \mathrm{~mL})$, THF $(40 \mathrm{~mL})$, THF-MeOH $(40 \mathrm{~mL})$, $\mathrm{MeOH}(40 \mathrm{~mL})$, THF $(40 \mathrm{~mL})$ and $\mathrm{CH}_{2} \mathrm{Cl}_{2}(50 \mathrm{~mL})$ and dried under reduced pressure at $40{ }^{\circ} \mathrm{C}$ for $24 \mathrm{~h}$. The intermediate polynorbornene-supported $t$-butyl prolinate, which was obtained as a white solid ( $892 \mathrm{mg}, 97 \%$ yield) [FTIR (ATR, neat): $v$ 2941, 2868, $1738(\mathrm{C}=\mathrm{O}), 1699(\mathrm{C}=\mathrm{O})$, 1476, 1453, 1393 ( $t$-butyl), 1393 ( $t$-butyl), $1254,1366 \mathrm{~cm}^{-1}$. Elemental Analysis (\%): Calcd.: N, 8.63. Found: $\mathrm{N}, 8.51 ; f=$ $1.52 \mathrm{mmol} \mathrm{g}^{-1}$ ], was directly submitted to the deprotection process. To this end, the prolinate $(870 \mathrm{mg})$ was swollen in $\mathrm{CH}_{2} \mathrm{Cl}_{2}(10 \mathrm{~mL})$, after $10 \mathrm{~min}$ TFA was added $(20 \mathrm{~mL})$ and the mixture was shaken at room temperature. When the IR bands of the $t$-butyl and carbonyl moieties in the protecting groups had completely disappeared, the reaction mixture was filtered off and the polymer was washed sequentially with THF (with $2 \%$ of $\left.\mathrm{Et}_{3} \mathrm{~N}, 50 \mathrm{~mL}\right), \mathrm{H}_{2} \mathrm{O}(50 \mathrm{~mL})$, THF $(50$ $\mathrm{mL})$, THF-MeOH 1:1 (50 mL), MeOH (50 mL), THF (50 $\mathrm{mL})$ and $\mathrm{CH}_{2} \mathrm{Cl}_{2}(50 \mathrm{~mL})$. The solid was dried under reduced pressure at $40{ }^{\circ} \mathrm{C}$ for $24 \mathrm{~h}(648 \mathrm{mg}, 98 \%$ yield $)$. FTIR (ATR, neat): v 3409 (COOH), 2942, 2866, 1622 
$(\mathrm{C}=\mathrm{O}), 1450,1371,1317,1219,1154 \mathrm{~cm}^{-1}$. Elemental Analysis (\%): Calcd.: N, 11.37; Found: N, 10.06; $f=1.80$

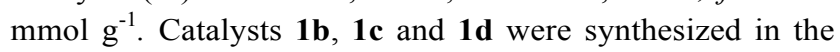
same way, starting from the corresponding azido-copolymer. 1b: The intermediate polynorbornene-supported $t$-butyl prolinate (a white solid) was obtained from 7 (1.0 g, 3.08 $\mathrm{mmol}), N, N$-diisopropylethylamine $(4.2 \mathrm{~mL}, 23.70 \mathrm{mmol})$, copper(I) iodide $(10 \mathrm{mg}, 0.059 \mathrm{mmol})$ and copolymer $4 \mathbf{b}$ (Copol-NB-NBCH $\mathrm{N}_{3} \mathrm{x} / \mathrm{y}=1.6: 1, \mathrm{n}=1 ; 1.0 \mathrm{~g}, f=2.37$ mmol $\left.\mathrm{g}^{-1}\right)$ in DMF:THF $1: 1(12 \mathrm{~mL})$ after $22 \mathrm{~h}$ reaction in 95\% yield (1.69 g). [FTIR (ATR, neat): $v$ 2943, 2867, 1737 $(\mathrm{C}=\mathrm{O}), 1699(\mathrm{C}=\mathrm{O}), 1476,1453,1392$ (t-butyl), 1365 ( $t$ butyl), 1255, $1217 \mathrm{~cm}^{-1}$. Elemental Analysis (\%): Calcd.: N, 7.50. Found: $\mathrm{N}, 7.67 ; f=1.37 \mathrm{mmol} \mathrm{g}^{-1}$ ]. Then final catalytic polymer 1b (1.18 g, 99\% yield) was obtained by shaking the intermediate prolinate $(1.50 \mathrm{~g})$ in $\mathrm{CH}_{2} \mathrm{Cl}_{2}(15 \mathrm{~mL})$ with TFA $(30 \mathrm{~mL})$. FTIR (ATR, neat): $v 3430(\mathrm{COOH}), 2942,2867$, $1631(\mathrm{C}=\mathrm{O}) \mathrm{cm}^{-1}$. Elemental Analysis (\%): Calcd.: N, 9.47. Found: $\mathrm{N}, 8.26 ; f=1.47 \mathrm{mmol} \mathrm{g}^{-1}$.

1c: The polynorbornene-supported $t$-butyl prolinate (a white solid) was obtained from $7(292 \mathrm{mg}, 0.89 \mathrm{mmol}), N, N$ diisopropylethylamine (1.2 $\mathrm{mL}, 6.90 \mathrm{mmol})$, copper(I) iodide $(3.3 \mathrm{mg}, 0.017 \mathrm{mmol})$ and copolymer $4 \mathrm{c}$ (Copol-NB$\left.\mathrm{NBCH}_{2} \mathrm{~N}_{3} \mathrm{x} / \mathrm{y}=1.3: 1, \mathrm{n}=1 ; 233 \mathrm{mg}, f=2.96 \mathrm{mmol} \mathrm{g}^{-1}\right)$ in DMF:THF 1:1 (6 mL) after $23 \mathrm{~h}$ reaction in $98 \%$ yield (464 mg). [FTIR (ATR, neat): v 2934, 2865, $1738(\mathrm{C}=\mathrm{O}), 1698$ $(\mathrm{C}=\mathrm{O}), 1476,1454,1393$ (t-butyl), 1365 (t-butyl), 1255, $1218 \mathrm{~cm}^{-1}$. Elemental Analysis (\%): Calcd.: N, 8.46. Found: $\left.\mathrm{N}, 8.75 ; f=1.56 \mathrm{mmol} \mathrm{g}^{-1}\right]$. Then final catalytic polymer $\mathbf{1 c}$ (365 mg, 98\% yield) was obtained by shaking the intermediate prolinate $(440 \mathrm{mg})$ in $\mathrm{CH}_{2} \mathrm{Cl}_{2}(4 \mathrm{~mL})$ with TFA $(8 \mathrm{~mL})$. FTIR (ATR, neat): $v 3416(\mathrm{COOH}), 2933,2863$, $1625(\mathrm{C}=\mathrm{O}) \mathrm{cm}^{-1}$. Elemental Analysis (\%): Calcd.: N, 11.04 . Found: $\mathrm{N}, 10.56 ; f=1.88 \mathrm{mmol} \mathrm{g}^{-1}$.

1d. The polynorbornene-supported $t$-butyl prolinate (a white solid) was obtained from $7(61 \mathrm{mg}, 0.19 \mathrm{mmol}), N, N$ diisopropylethylamine (250 $\mathrm{mL}, 1.43 \mathrm{mmol})$, copper(I) iodide (1 mg, $5.74 \mathrm{mmol}$ ) and copolymer 4d (Copol-NB$\mathrm{NB}\left(\mathrm{CH}_{2}\right)_{4} \mathrm{~N}_{3} \mathrm{x} / \mathrm{y}=24.1: 1, \mathrm{n}=4 ; 300 \mathrm{mg}, f=0.478 \mathrm{mmol} \mathrm{g}^{-}$ $\left.{ }^{1}\right)$ in DMF:THF $1: 1(2 \mathrm{~mL})$ after $24 \mathrm{~h}$ reaction in $92 \%$ yield (320 mg). [FTIR (ATR, neat): $v$ 2940, 2865, $1743(\mathrm{C}=\mathrm{O})$, $1707(\mathrm{C}=\mathrm{O}), 1451,1392$ ( $t$-butyl), 1366 ( $t$-butyl), 1255, 1218 $\mathrm{cm}^{-1}$. Elemental Analysis (\%): Calcd.: N, 2.31. Found: N, $\left.1.91 ; f=0.34 \mathrm{mmol} \mathrm{g}^{-1}\right]$. Then final catalytic polymer 1d (280 mg, 98\% yield) was obtained by shaking the intermediate prolinate $(300 \mathrm{mg})$ in $\mathrm{CH}_{2} \mathrm{Cl}_{2}(4 \mathrm{~mL})$ with TFA (8 mL). FTIR (ATR, neat): $v$ 2940, 2864, $1620(\mathrm{C}=\mathrm{O}) \mathrm{cm}^{-1}$. Elemental Analysis (\%): Calcd.: N, 2.48. Found: N, 2.09; $f=$ $0.37 \mathrm{mmol} \mathrm{g}^{-1}$.

\section{Synthesis of polymer $6 \mathrm{~b}$.}

Bromoalkyl polynorbornene 3b (Copol-NB-NBCH ${ }_{2} \mathrm{Br}, \mathrm{x} / \mathrm{y}$ $\left.=1.6: 1,330 \mathrm{mg}, f=2.98 \mathrm{mmol} \mathrm{g}^{-1}\right)$, toluene $(21 \mathrm{~mL}), p$ ethynylbenzoic acid $(5,393 \mathrm{mg}, 2.69 \mathrm{mmol})$ and DBU $(0.41$ $\mathrm{mL}, 2.69 \mathrm{mmol}$ ) were mixed in a flask under $\mathrm{N}_{2}$, and the mixture was heated under reflux for $22 \mathrm{~h}$. The solvent was evaporated and $\mathrm{MeOH}$ was added $(30 \mathrm{~mL})$. A solid appeared, which was stirred for $30 \mathrm{~min}$, filtered, washed with $\mathrm{MeOH}(2 \times 30 \mathrm{~mL})$ and dried under reduced pressure at $40{ }^{\circ} \mathrm{C}$ for $24 \mathrm{~h}$. Compound $\mathbf{6 b}$ was obtained as a white solid (375 mg) soluble in dichloromethane or THF, which contained $73.3 \mathrm{mg}$ of $\mathrm{Br} / \mathrm{g}$ of copolymer, indicating that substitution has proceeded to a $69 \%$ degree. ${ }^{13} \mathrm{C}$ NMR (gelphase, $\left.126 \mathrm{MHz}, \mathrm{CDCl}_{3}\right): \delta 166.3(\mathrm{C}=\mathrm{O}), 132.2,130.6$, $129.6,126.9,83.0(\mathrm{C}=\mathrm{C}), 80.2(\mathrm{C}=\mathrm{C}), 56-52.8$ (br), 52.250.2 (br), 47.9-45.9 (br), 43.7-41.6 (br), 40.2-38.6 (br), 36.834.4 (br), 32.2-31.0, 30.6-29.0 (br), 28.7-28.3 (br) ppm. Raman: $v 2100(\mathrm{C}=\mathrm{C}), 1720,1600,638(\mathrm{C}-\mathrm{Br}) \mathrm{cm}^{-1}$. FTIR (ATR, neat): v $3301(=\mathrm{CH}), 2942,2866,1719(\mathrm{C}=\mathrm{O}), 1607$, 1266 (C-O), 1173, 1094, 857, $768 \mathrm{~cm}^{-1}$.

\section{Synthesis of catalyst 2.}

$(2 S, 4 R)-N$-Boc-4-azido-L-proline tert-butyl ester $8(151 \mathrm{mg}$, $0.48 \mathrm{mmol}), \quad N, N$-diisopropylethylamine $(650 \mathrm{~mL}, 3.72$ $\mathrm{mmol}$ ) and copper(I) iodide ( $2 \mathrm{mg}, 9.3 \mathrm{mmol})$ were added to a solution of 4-ethynylphenyl-polynorbornene copolymer $\mathbf{6 b}$ $(220 \mathrm{mg})$ in THF $(1.5 \mathrm{~mL})$ placed in a flask under $\mathrm{N}_{2}$. The reaction mixture was shaken at $40{ }^{\circ} \mathrm{C}$ for $24 \mathrm{~h}$, the reaction progress being monitored by FTIR. When the IR band of the alkynyl group had completely disappeared, the polymer was collected by filtration, sequentially washed with $\mathrm{H}_{2} \mathrm{O}$ (20 $\mathrm{mL})$, THF (20 mL), THF-MeOH (20 mL), MeOH (20 mL), THF $(20 \mathrm{~mL})$ and $\mathrm{CH}_{2} \mathrm{Cl}_{2}(20 \mathrm{~mL})$ and dried under reduced pressure at $40{ }^{\circ} \mathrm{C}$ for $24 \mathrm{~h}$. The polynorbornene-supported prolinate was obtained as an insoluble white solid (320 mg). [FTIR (ATR, neat): $v$ 2942, 2867, $1709(\mathrm{C}=\mathrm{O}), 1614(\mathrm{C}=\mathrm{O})$, 1392 (t-butyl), 1367 (t-butyl), $1266(\mathrm{C}-\mathrm{O}) \mathrm{cm}^{-1}$. Elemental Analysis (\%): Found: $\left.\mathrm{N}, 5.05 ; f=0.90 \mathrm{mmol} \mathrm{g}^{-1}\right]$. Then polymer $2(250 \mathrm{mg})$ was obtained by shaken the prolinate $(200 \mathrm{mg})$ in $\mathrm{CH}_{2} \mathrm{Cl}_{2}(1.5 \mathrm{~mL})$ with TFA $(1.5 \mathrm{~mL})$. When the IR bands of the $t$-butyl and carbonyl moieties in the protecting groups had completely disappeared, the reaction mixture was filtered off and the polymer was washed sequentially with THF (with $2 \%$ of $\left.\mathrm{Et}_{3} \mathrm{~N}, 20 \mathrm{~mL}\right), \mathrm{H}_{2} \mathrm{O}(20$ $\mathrm{mL})$, THF (20 mL), THF-MeOH 1:1 (20 mL), MeOH (20 $\mathrm{mL})$, THF $(20 \mathrm{~mL})$ and $\mathrm{CH}_{2} \mathrm{Cl}_{2}(20 \mathrm{~mL})$. The solid was dried under reduced pressure at $40{ }^{\circ} \mathrm{C}$ for $24 \mathrm{~h}$. FTIR (ATR, neat): $v 3431(\mathrm{COOH}), 2943,2865,1717(\mathrm{C}=\mathrm{O}), 1615$ $(\mathrm{C}=\mathrm{O}), 1449,1267(\mathrm{C}-\mathrm{O}), 1177,1100,771 \mathrm{~cm}^{-1}$. Elemental Analysis (\%): Found.: $\mathrm{N}, 4.89 ; f=0.87 \mathrm{mmol} \mathrm{g}^{-1}$.

\section{General procedure for the asymmetric aldol reaction catalyzed by polymers 1a-d.}

Polynorbornene-supported proline $1(0.015 \mathrm{mmol})$ was swollen in $54 \mathrm{~mL}$ of a DMSO/ $\mathrm{H}_{2} \mathrm{O}$ (87:13) mixture containing TFA $(0.015 \mathrm{mmol})$. The corresponding aldehyde 9a-j $(0.15 \mathrm{mmol})$ and cyclohexanone $(0.75 \mathrm{mmol})$ were added and the reaction mixture was shaken at room temperature. When the reaction is completed (see Table 3 and Scheme 4), dichloromethane ( $1 \mathrm{~mL}$ ) was added and the polymer was filtered off, washed with water $(2 \mathrm{~mL})$ and dichloromethane $(2 \mathrm{~mL})$ and air-dried. The aqueous filtrate 
was separated by decantation and extracted with dichloromethane ( $3 \times 10 \mathrm{~mL})$. The combined organic phases were washed with brine, dried $\left(\mathrm{MgSO}_{4}\right)$ and concentrated under reduced pressure.

Purification by flash column chromatography (ethyl acetate/hexanes, 9:1 to 4:1) gave the aldol products 11aj as mixtures of anti and syn diastereomers. Conversion and diastereomeric ratio were determined by ${ }^{1} \mathrm{H}$ NMR spectroscopy on the crude samples after polymer removal. The enantiomeric excess was determined by HPLC on a chiral stationary phase after purification by flash column chromatography on silicagel.

\section{General procedure for the asymmetric aldol reaction catalyzed by polymer 2 .}

Polynorbornene-supported proline $2(0.015 \mathrm{mmol})$ was swollen in a mixture of $\mathrm{DMF} / \mathrm{H}_{2} \mathrm{O}(50: 50,54 \mu \mathrm{L})$. The corresponding aldehyde $9 \mathbf{a}-\mathbf{j}(0.15 \mathrm{mmol})$ and ketone 10a-c $(0.75 \mathrm{mmol})$ were added and the reaction mixture was stirred at room temperature (see Scheme 5). After the indicated time, dichloromethane $(1 \mathrm{~mL})$ was added and the polymer was filtered off, washed with water $(2 \mathrm{~mL})$ and dichloromethane $(2 \mathrm{~mL})$ and air-dried. The aqueous filtrate was separated by decantation and extracted with dichloromethane $(3 \times 10 \mathrm{~mL})$. The combined organic phases were washed with brine, dried $\left(\mathrm{MgSO}_{4}\right)$ and concentrated under reduced pressure. When required, purification by flash column chromatography (ethyl acetate/hexanes, 9:1 to 4:1) was performed to give the aldol products 11a-l as mixtures of anti and syn diastereomers. Conversion and diastereomeric ratio were determined by ${ }^{1} \mathrm{H}$ NMR spectroscopy on the crude samples after polymer removal. The enantiomeric excess was determined by HPLC on a chiral stationary phase after purification by flash column chromatography on silicagel.

\section{Acknowledgements}

Financial support from Institute of Chemical Research of Catalonia (ICIQ) Foundation, the Spanish MINECO (DGI, grants CTQ2013-48406-P and CTQ2012-38594-C02-01), DEC-Generalitat de Catalunya (Grant 2014SGR827) and the Junta de Castilla y León (grant VA373A11-2) is gratefully acknowledged. We also thank MINECO for support through Severo Ochoa Excellence Accreditation 2014-2018 (SEV2013-0319). The authors thank Dr. Carles Lizandara for valuable support in the characterization of polymers.

\section{Notes and references}

${ }^{a}$ Institute of Chemical Research of Catalonia (ICIQ), Av. Països Catalans 16, 43007 Tarragona, Spain. Fax: (+34)977920244; E-mail: mapericas@iciq.es

${ }^{b}$ IU CINQUIMA/Química Inorgánica, Universidad de Valladolid, 47071 Valladolid, Spain. E-mail: albeniz@qi.uva.es

${ }^{c}$ Departament de Química Orgànica, Universitat de Barcelona, 08028 Barcelona, Spain. $\dagger$ Electronic Supplementary Information (ESI) available: Preparation of compound 5, screening of additives and solvent and temperature effects on the aldol reaction between 9a and 10a, recycling experiments, spectroscopic and chromatographic data of the aldol products, and characterization of the polymers are provided. See DOI: $10.1039 / \mathrm{b} 000000 \mathrm{x} /$

1 For reviews about polymer-supported catalysts, see: (a) Handbook of Green Chemistry \& Technology, eds. J. Clark and D. Mcquarrie, Blackwell Publ., London, 2002; (b) N. E. Leadbeater and M. Marco, Chem. Rev. 2002, 102, 3217; (c) C. A. McNamara, M. J. Dixon and M. Bradley, Chem. Rev. 2002, 102, 3275; (d) Polymeric materials in organic synthesis and catalysis, ed. M. R. Buchmeiser, WileyVCH, Weinheim, 2003; (e) M. Benaglia, A. Puglisi and F. Cozzi, Chem. Rev. 2003, 103, 3401; (f) R. Haag and S. Roller, Immobilized Catalysts in: Topics in Current Chemistry, ed. A. Kirsching, Springer, Heidelberg, 2004; (g) Polymer-Supported Reagents and Catalysts: Increasingly Important Tools for Organic Synthesis, eds. P. H. Toy and M. Shi, Tetrahedron 2005, 61, 12013; (h) B. M. L. Dioos, I. F. J. Vankelecom and P. A. Jacobs, $A d v$. Synth. Catal. 2006, 348, 1413; (i) S. Itsuno and N. Haraguchi, Heterogeneous Enantioselective Catalysis Using Organic Polymeric Supports in Handbook of Asymmetric Heterogeneous Catalysis, eds. K. Ding and Y. Uozumi, Wiley-VCH, Weinheim, 2008; (j) Recoverable and Recyclable Catalysts, ed. M. Benaglia, John Wiley \& Sons, Chichester, 2009; $(k)$ K. E. Kristensen and T. Hansen, Eur. J. Org. Chem. 2010, 3179.

2 C. Jimeno, S. Sayalero and M. A. Pericàs, Covalent Heterogenization of Asymmetric Catalysts on Polymers and Nanoparticles in Heterogenized Homogeneous Catalysts for Fine Chemicals Production. Catalysis by Metal Complexes, eds. P. Barbaro and F. Liguari, Springer, Heidelberg, 2010, Vol. 33, chapter 4, pp. 123-170.

3 F. Cozzi, Adv. Synth. Catal. 2006, 348, 1367.

4 J. Lu and P. H. Toy, Chem. Rev. 2009, 109, 815.

5 (a) S. Martínez-Arranz, A. C. Albéniz and P. Espinet, Macromolecules 2010, 43, 7482; (b) A. C. Albéniz, S. Martínez-Arranz and P. Espinet, ES2364781A1.

6 For examples of the use of tin reagents supported on vinyl addition polynorbornes in the Stille reaction see: $(a) \mathrm{S}$. Martínez-Arranz, N. Carrera, A. C. Albéniz, P. Espinet and A. Vidal-Moya, Adv. Synth. Catal. 2012, 354, 3551; (b) I. Meana, A. C. Albéniz and P. Espinet, Adv. Synth. Catal. 2010, 352, 2887; (c) N. Carrera, E. Gutierrez, R. Benavente, M. M. Villavieja, A. C. Albéniz and P. Espinet, Chem. Eur. J. 2008, 14, 10141.

7 For recent examples see: (a) E. Alza, S. Sayalero, X. C. Cambeiro, R. Martín-Rapún, P. O. Miranda and M. A. Pericàs, Synlett 2011, 464; (b) X. C. Cambeiro, R. MartínRapún, P. O. Miranda, S. Sayalero, E. Alza, P. Llanes and M. A. Pericàs, Beilstein J. Org. Chem. 2011, 7, 1486; (c) C. Ayats, A. H. Henseler and M. A. Pericàs, ChemSusChem 2012, 5, 320; (d) X. Fan, S. Sayalero and M. A. Pericàs, 
Adv. Synth. Catal. 2012, 354, 2971; (e) P. Kasaplar, C. Rodríguez-Escrich and M. A. Pericàs, Org. Lett. 2013, 15, 3498; ( $f$ ) R. Martín-Rapún, S. Sayalero and M. A. Pericàs, Green Chem. 2013, 15, 3295; ( $g$ ) X. Fan, C. RodríguezEscrich, S. Sayalero and M. A Pericàs, Chem. Eur. J. 2013, 19, 10814; (h) L. Osorio-Planes, C. Rodríguez-Escrich and M. A. Pericàs, Chem. Eur. J. 2014, 20, 2397.

(a) Modern Aldol Reactions, ed. R. Mahrwald, WileyVCH, Weinheim, 2004. For selected examples see: (b) D. Font, C. Jimeno and M. A. Pericàs, Org. Lett. 2006, 8, 4653; (c) D. Font, S. Sayalero, C. Jimeno and M. A. Pericàs, Org. Lett. 2008, 10, 337.

9 (a) Centenary Lecture - 1,3-Dipolar Cycloadditions, R. Huisgen, Proc. Chem. Soc. London 1961, 357; (b) R. Huisgen, 1,3-Dipolar Cycloaddition Chemistry, ed. A. Padwa, Wiley, New York, 1984; (c) M. Meldal and C. W. Tornøe, Chem. Rev. 2008, 108, 2952.

10 P. P. Chu, W.-J. Huang, F.-C. Chang and S. Y. Fan, Polymer 2000, 41, 401.

11 The functionalization of a given resin can be calculated from the results of elemental analysis with the formulae: For nitrogen containing functional resins: $f\left(\mathrm{mmol} \mathrm{g}^{-1}\right)=$ $0.714(\% \mathrm{~N}) / \mathrm{n}_{\mathrm{N}},(\% \mathrm{~N})$ representing the weight percentage of nitrogen determined by elemental analysis and $n_{N}$ representing the number of nitrogen atoms in the functional unit; For bromine containing functional resins: $f\left(\mathrm{mmol} \mathrm{g}^{-1}\right)$ $=0.125(\% \mathrm{Br}) / \mathrm{n}_{\mathrm{Br}}, \quad(\% \mathrm{Br})$ representing the weight percentage of bromine determined by elemental analysis and $\mathrm{n}_{\mathrm{Br}}$ representing the number of bromine atoms in the functional unit.

12 (a) The maximal functionalization $\left(f_{\max }\right)$ of a given resin can be calculated from the functionalization of a precursor resin $\left(f_{0}\right)$ by means of the following formula: $f_{\max }\left(\mathrm{mmol} \mathrm{g}^{-}\right.$ $\left.{ }^{1}\right)=f_{0} /\left(1+f_{0}(\Delta \mathrm{MW} / 1000)\right.$, where $\Delta \mathrm{MW}$ represents the variation in molecular mass of the functional unit along the considered transformation(s); (b) Yield in reactions involving functional resins is not related to mass recovery, which is generally complete, but rather to the ratio between actual functionalization $(f)$ and maximal functionalization $\left(f_{\max }\right)$ for the resin undergoing the considered process: yield $(\%)=100\left(f / f_{\max }\right)$.

13 The equilibrium swelling ratio (SR) in each solvent was determined gravimetrically with the formula: Swelling Ratio $(\mathrm{SR}, \%)=100\left(\mathrm{~W}_{\mathrm{s}}-\mathrm{W}_{\text {dry }}\right) / \mathrm{W}_{\text {dry }}$, where $\mathrm{W}_{\mathrm{s}}$ is the weight of swollen samples after the certain time and $\mathrm{W}_{\text {dry }}$ is the weight of dried samples.

14 P. M. Pinko, K. M. Laurikainen, A. Usano, A. I. Nyberg and J. A. Kaavi, Tetrahedron 2006, 62, 317.

15 For the role of concentration effect in solvent-free aldol reactions, see: (a) B. Rodríguez, T. Rantanen and C. Bolm, Angew. Chem. Int. Ed. 2006, 45, 6924; (b) B. Rodríguez, A. Bruckmann and C. Bolm, Chem. Eur. J. 2007,13, 4710.

16 J. Rudolph, N. Hermanns and C. Bolm, J. Org. Chem. 2004, 69, 3997.

17 For linear supports, see: (a) Y.-X. Liu, Y.-N. Sun, H.-H. Tan, W. Liu and J.-C. Tao, Tetrahedron: Asymmetry 2007,
18, 2649. (b) Y.-X. Liu, Y.-N. Sun, H.-H. Tan and J.-C. Tao, Catal. Lett. 2008, 120, 281. For cross-linked supports, see: (c) F. Giacalone, M. Gruttadauria, A. M. Marculescu and R. Noto, Tetrahedron Lett. 2007, 48, 255; (d) M. Gruttadauria, F. Giacalone, A. M. Marculescu, P. Lo Meo, S. Riela and R. Noto, Eur. J. Org. Chem. 2007, 4688. For acrylic polymers, see: (e) T. E. Kristensen, K. Vestli, K. A. Fredriksen, F. K. Hansen and T. Hansen, Org. Lett. 2009, 11, 2968; (f) T. E. Kristensen, K. Vestli, M. G. Jakobsen, F. K. Hansen and T. Hansen, J. Org. Chem. 2010, 75, 1620.

18 Y. Hayashi, T. Sumiya, J. Takahashi, H. Gotoh, T. Urushima and M. Shoji, Angew. Chem. Int. Ed. 2006, 45, 958.

19 (a) M. Gruttadauria, F. Giacalone and R. Noto, Adv. Synth. Catal. 2009, 351, 33; (b) J. Paradowska, M. Stodulski and J. Mlynarski, Angew. Chem. Int. Ed. 2009, 48, 4288; (c) M. Raj and V. K. Singh, Chem. Commun. 2009, 44, 6687.

20 K. Sakthivel, W. Notz, T. Bui and C. F. Barbas, III, J. Am. Chem. Soc. 2001, 123, 5260. 